\title{
Medium Molecular Weight Chitosan as a Carrier for Delivery of Lincomycin Hydrochloride from Intra-pocket Dental Film: Design, Development, in vitro and ex vivo Characterization
}

\author{
Reetika Ganjoo ${ }^{1}$, Shashank Soni ${ }^{1 *}$, Veerma Ram ${ }^{1}$, Anurag Verma ${ }^{2}$ \\ ${ }^{1}$ School of Pharmaceutical Sciences, Sardar Bhagwan Singh PG Institute of Biomedical Sciences and Research, Dehradun, India. \\ ${ }^{2}$ School of Pharmaceutical Sciences, IFTM University, Moradabad, India.
}

\begin{tabular}{l} 
ARTICLE INFO \\
\hline Article history: \\
Received on: 09/05/2016 \\
Revised on: 24/06/2016 \\
Accepted on: 12/07/2016 \\
Available online: $29 / 10 / 2016$ \\
\hline Key words: \\
Medium Molecular Weight \\
Chitosan; Lincomycin \\
Hydrochloride; Intra pocket \\
dental film; static in vitro \\
release studies; ex vivo \\
diffusion study; Akaike \\
Information Criteria.
\end{tabular}

\begin{abstract}
The purpose of investigation is to find out the potential of Medium Molecular Weight Chitosan (MMWCH) loaded with Lincomycin Hydrochloride (LNC) having pKa 7.6 and $\log p$ value 0.20 for treatment of periodontitis and gingivitis, prepared by using solvent casting technology in form of intra pocket dental film. Four sets of formulation were prepared and each set comprises of four formulations each. The formulations were evaluated for drug content uniformity, weight uniformity, thickness of patch, surface $\mathrm{pH}$, moisture loss, swelling index, water vapor transmission rate, static in vitro release studies using diffusion cell, ex vivo flux study using diffusion cell by help of excised gum lining of goat, release kinetics and Akaike Information Criteria; goodness of fit (AIC) value determination. Excipient drug interaction was carried out by using Fourier Transform Infrared spectroscopy (FTIR), and by Thermo gravimetric Analysis (TGA)/Differential thermal analysis (DTA)/Derivative thermo gravimetric analysis (DTG) and this suggests that there is no drug excipient interaction occurs. The drug release studies show the sustained release without any burst effect for consecu tive 5 days. Formulation R1, R2, R7, R8, R9, R10, R13 and R14 and follows the zero order release pattern and formulation R3, R4, R5, R6, R11, R12, R15 and R16 follows the Higuchi model because they have lower AIC value and higher $\mathrm{r}^{2}$ value. Formulation ER17, ER18, ER19 and ER20 is having the average flux of 1.0, 1.48, 1.35 and $1.45 \mathrm{mg} / \mathrm{cm}^{2} \mathrm{hr}^{-1}$ respectively, and when compared statistically student's paired t-test these all formulations are significantly different from each other.
\end{abstract}

\section{INTRODUCTION}

The two major kinds of inflammatory diseases affecting the periodontium are periodontitis and gingivitis. The formation of periodontal pockets (lesions between teeth and junction epithelium) occurs as a consequence of a localized bacterial pathogenic bacterial infection under the gum line (Li et al., 2000). Gingivitis occurs due to inflammation of the gingival that does not lead to the clinical attachment loss by affecting the

\footnotetext{
* Corresponding Author

Shashank Soni, School of Pharmaceutical Sciences, Sardar Bhagwan Singh PG Institute of Biomedical Sciences and Research, Dehradun, India.E mail: shashank_soni64 @ yahoo.com
}

surrounding tissues. Periodontitis is inflammation of the gingival and adjacent attachment apparatus and is characterized by loss of connective tissue attachment and alveolar bone. It occurs mainly due to the uncontrolled growth of anaerobic micro-organisms in subgingiva and if unchecked, results in permanent tooth loss as it destroys the supporting structure of the teeth by damaging the bone and soft tissues (Loesche et al., 2001). On that point are more or less commercially available subgingiva delivery systems such as Perio-Chip, which can be inserted into the periodontal pocket. In the later stages of this disease, the supporting collagen of the periodontium is degenerated, the alveolar bone begins to resolve and gingival epithelium migrates along the tooth surface forming a "periodontal pocket" (Soskolne et al., 1997; Polson et al., 1997). 
This periodontal pocket provides ideal conditions for proliferation of various micro-organisms, especially gram negative, facultative anaerobic species. Prominent among these includes Bacteroides spp, B. intermediates, and B. gingivalis (Schwach-Abdellaoui et al., 2000; Takasaki et al., 2009). One of the best methods designed for the treatment of periodontal disease is the treatment through dental films/strips/patches (Norling et al., 1992).

Films are matrix delivery systems in which the drug is distributed throughout the polymer and the drug release occurs by diffusion and/or matrix dissolution or erosion (Ahmed et al., 2009). The dimensions and shape of films can be controlled so as to correspond to the dimensions of the pocket where the film is to be inserted. It can be quickly inserted into the sac with minimal pain to the patient. It can be completely submersed in the pocket and can be inserted into the base of pocket (Johnston et al., 2013). Following are the criteria for designing the dental films such as they have to be small, since the average pocket depth is between 6$10 \mathrm{~mm}$ and it cannot be exposed beyond the gingival margin when inserted into the periodontal pocket, it should not cause any interference with the normal oral hygiene, the active ingredient in the prepared film should display therapeutic effectiveness at a slow rate so as to obtain a sustained effect and antimicrobial drug should be highly specific against the various bacteria present in the pocket (Jeffcoat et al., 1998).

Systemic administration of drugs leads to therapeutic concentrations at the site of infection, but for shorter periods of time, forcing repeated dosing for longer time points. The function of sustained release formulations to deliver anti-microbial to the site of infection (periodontal pocket) has recently gained wide interest (Slots et al., 1990). These products offer a long term, effective treatment at the site of infection at much smaller doses. Biodegradable polymers are extensively employed in periodontal drug delivery devices because of their abundant source, lack of toxicity, and high tissue compatibility. These cases of drug delivery systems also experience an increased contact time with the site of infection, unlike gels or other such preparations and are not washed away by saliva (Lu et al., 2004).

In order to achieve sustained and control actions of drugs, Medium Molecular Weight Chitosan (MMWCH) was used which is a polycationic polymer obtained from alkaline deacetylation of chitin. It is utilized to provide the prolonged the effect of LNC at the targeted site (Sato et al., 2001). MMWCH chooses on the basis of their superior biological activities including biodegradability, antioxidant and antibacterial activity. It provides various possibilities for derivatization and grafting of desirable ones due to the presence of a large number of hydroxyl and amino groups. It is able of interacting chemically with the gum lining or the tissues which increases the residence time in the mouth and consequently increases the bioavailability of the incorporated drug (Ikinci et al., 2002, Zhou et al., 2010, Rinaudo et al., 2006).

Lincomycin hydrochloride (LNC), a systemic antibiotic, belongs to the class of lincosamides, is active against most of the gram positive bacteria. LNC inhibits cell growth and microbial protein synthesis, by interacting strongly and specifically with the 50S ribosomal subunits (Panigrahi et al., 2006; Peschke et al., 1995). It is available as injections and capsules. However, intravenous or intramuscular administration of LNC has short biological half life of $5.4 \pm 1.0$ hours for its relatively high molecular weight $(\mathrm{MW}=406.537)$ and typical computed physical properties like dissociation constant pKa 7.6, water solubility 29.3 $\mathrm{mg} / \mathrm{ml}$ and experimental $\log P$ value is 0.20 . Furthermore, there is not well reported about the metabolism of LNC because they are not fully characterized, and the oral absorption bioavailability is 20 to $30 \%$ during fasting state and decreases during the fed state (Argoudelis et al., 1964). These undesirable side effects of LNC could be decreased by delivering to the dental route. However, the dental barrier needs to overcome.

In this article we investigated the potential of $\mathrm{MMWCH}$ and LNC loaded dental patches in Simulated Gingival Fluid (SGF; $\mathrm{pH}$ 6.6). These MMWCH-LNC loaded patches represented novelty in the field of pharmaceutical technology due to their performance in the in vitro and ex vivo release studies. The hydrophilic drug was leached from the patches for a longer period of time without leading to the burst release. The reason for not inducing burst release due to the very high cross linking of MMWCH polymeric matrices which holds the LNC for a longer period of time. Moreover, the patches also show the originality in the field of dentistry, since, nowadays, there are not in the pharmaceutical market mucoadhesive inserts are capable and prolonging the dental delivery of antibiotic drug in order to reduce the local infection and increasing the patient compliance to the therapy.

\section{MATERIALS AND METHODS}

\section{Materials and Equipments}

Lincomycin Hydrochloride (LNC) was procured from Yarrow Chem; Mumbai, India. Medium Molecular Weight Chitosan; M.W. 190,000-310,000 (MMWCH; Degree of Deacetylation $75-85 \%$, apparent viscosity $200-800 \mathrm{cP}$ at $25{ }^{\circ} \mathrm{C}$, Brookfield) was procured from Sigma Aldrich St. Louis, USA. Ultra pure water (Maxima ultra pure water, UK) with a resistivity more than $18 \mathrm{M} \Omega / \mathrm{cm}$ was used during the preparation of all the formulation solutions. Chloroform, Ethyl Cellulose; EC, Hydroxypropyl methyl cellulose; HPMC, Glycerol, Poly vinyl alcohol; PVA, Agar and Di-butyl phthalate were purchased from Central Drug House; Mumbai, India. All other chemicals and reagents used were of analytical grade. Equipments used for carrying out this study are UV-spectrophotometer; double beam (Shimadzu, UV-1800) which was previously validated, Diffusion cell apparatus; 7 cell (Electrolab, EDC-07), pH meter (Mettler Tolido, SG-23), Thickness tester (Mitutoyo corporation, MDC25SB).

\section{Preparation of Dental Films Fabricated with Polymer}

The method used for the preparation was solvent casting method. Weighed quantity of MMWCH was taken as mentioned in 
table 1, dissolved thoroughly in sufficient quantity of Ultra pure water. After homogeneous mixtures obtained add Poly Vinyl Alcohol (PVA) solution (previously dissolved in hot water) mixed using a magnetic stirrer at $150 \mathrm{rpm}$ by using teflon coated magnetic bead. Required quantities of LNC were weighed and dissolve in $2 \mathrm{ml}$ of ultra pure water and pour into the above polymeric solution mix thoroughly over a magnetic stirrer and kept aside for $10 \mathrm{~min}$ for saturation of solution and sonicated for $10 \mathrm{~min}$. to remove the bubbles formed during the process of dental film. This solution poured into a petriplate that was applied lubricant glycerol. Keep the petriplate at room temperature to evaporate solvent from the solution. The formed dental films are removed from petriplate and kept in desiccator containing anhydrous calcium chloride for further use. In this total 4 sets are prepared by solvent casting method (R1-R4), Direct cross-linking with glutraldehyde (R5-R8), Indirect cross-linking with glutraldehyde in Thin Layer Chromatography (TLC) chamber (R9R12), Sandwich method using backing layer of HPMC (R13-R16).

Table 1: Design and optimization of the formulation composition of Dental Films of Lincomycin hydrochloride.

\begin{tabular}{llllll} 
& & & & \\
$\mathrm{R} 1$ & 25 & 50 & 300 & 0.5 & 0.5 \\
$\mathrm{R} 2$ & 25 & 50 & 330 & 0.5 & - \\
$\mathrm{R} 3$ & 25 & 50 & 360 & 0.5 & - \\
$\mathrm{R} 4$ & 25 & 50 & 390 & 0.5 & 0.5 \\
$\mathrm{R} 5$ & 25 & 50 & 300 & 0.5 & 0.5 \\
$\mathrm{R} 6$ & 25 & 50 & 330 & 0.5 & - \\
$\mathrm{R} 7$ & 25 & 50 & 360 & 0.5 & - \\
$\mathrm{R} 8$ & 25 & 50 & 390 & 0.5 & 0.5 \\
$\mathrm{R} 9$ & 25 & 50 & 300 & 0.5 & 0.5 \\
$\mathrm{R} 10$ & 25 & 50 & 330 & 0.5 & - \\
$\mathrm{R} 11$ & 25 & 50 & 360 & 0.5 & - \\
$\mathrm{R} 12$ & 25 & 50 & 390 & 0.5 & 0.5 \\
$\mathrm{R} 13$ & 25 & 50 & 300 & 0.5 & 0.5 \\
$\mathrm{R} 14$ & 25 & 50 & 330 & 0.5 & - \\
$\mathrm{R} 15$ & 25 & 50 & 360 & 0.5 & - \\
$\mathrm{R} 16$ & 25 & 50 & 390 & 0.5 & 0.5 \\
\hline & & & & & - \\
\hline
\end{tabular}

\section{CHARACTERIZATION TECHNIQUES}

\section{Functional group characterization by Fourier Transform Infrared spectroscopy (FTIR)}

Fourier Transform Infrared spectroscopy (FTIR) was performed by BX2; Perkin Elmer, Norwalk, USA. The FTIR analysis was carried out for qualitative compound identification and to ascertain that there is any drug excipient interaction occurs or not and secondly to confirm the presence of functional group in the compound and its comparison to official compendium. The method involved is of direct compression technique by using potassium bromide; $\mathrm{KBr}$. The $\mathrm{KBr}$ pellet of approximately $1 \mathrm{~mm}$ diameter of the drug was prepared grinding 3-5 $\mathrm{mg}$ of sample with $100-150 \mathrm{mg}$ of $\mathrm{KBr}$ in pressure compression machine. The sample pellet was mounted in FTIR compartment and taken scan at wavelength $4000 \mathrm{~cm}^{-1}-400 \mathrm{~cm}^{-1}$ (Tiwari et al., 2015, Soni et al., 2016).

\section{Thermo analytical characterization}

Thermo analytical characterization was performed on EXSTAR TG/DTA 6300 and it includes Thermo Gravimetric Analysis (TGA), Differential Thermal Analysis (DTA) and Derivative Thermo Gravimetric Analysis (DTG), having sensitivity of $0.2 \mu \mathrm{g}$ for TGA and $0.06 \mu \mathrm{V}$ for DTA. It was carried out to study the determination of characteristics peaks (endothermic and exothermic) and heat of melting was recorded of drug, excipient and drug-excipient mixtures in present investigation. The study was carried out at $5^{\circ} \mathrm{C} / \mathrm{min}$ till melting point in the presence of inert nitrogen $\left(\mathrm{N}_{2}\right)$ using duplicate sample of $5 \mathrm{mg}$ in crimped aluminum pan. Flow rate of purge gas is 2ml/minute (Tiwari et al., 2015; Soni et al., 2016).

\section{Surface pH}

The prepared films were left to swell on the agar plate, prepared by dissolving $2 \% \mathrm{w} / \mathrm{v}$ agar in warmed distilled water with constant stirring and poured into petriplate to solidify at room temperature. Surface $\mathrm{pH}$ was measured with the help of $\mathrm{pH}$ electrode placed on the surface of swollen film. Mean of three readings was recorded. The main purpose of this study is to determine whether the formulation is acidic or basic, the acidic and basic nature can cause the irritation when placed inside the cavity, so the formulation $\mathrm{pH}$ must close to the neutral $\mathrm{pH}$ (Baier et al., 1978, Rhim et al., 2006, Bumgardner et al., 2003).

\section{Weight uniformity of the films}

Twenty films of size $(6 \times 2 \mathrm{~mm})$ were taken from the different areas of the film and weighed on the electronic weighing balance (Shimadzu). Then the weight was recorded and average weight range, standard deviation and variation from the average reading was calculated (Baier et al., 1978, Rhim et al., 2006, Bumgardner et al., 2003).

\section{Drug content}

Size of $(6 \times 2 \mathrm{~mm})$ was cut from the total film area. This film was soaked in simulated gingival fluid $(\mathrm{pH}$ 6.6) and this solution is for shaken over bath shaker for 24 hours at room temperature followed by centrifugation at $2000 \mathrm{rpm}$ (Remi Centrifuge); supernatant was filtered with $0.45 \mu \mathrm{m}$ membrane filter and suitably diluted (Baier et al., 1978, Rhim et al., 2006, Bumgardner et al., 2003). The absorbance of the resulting solutions was recorded at absorption maxima $212 \mathrm{~nm}$.

\section{Folding endurance}

Folding endurance of the film was determined by repeatedly folding strip of the size $(6 \times 2 \mathrm{~mm})$ from same place, till it broke (Baier et al., 1978; Rhim et al., 2006; Bumgardner et al., 2003). 


\section{Moisture Loss}

Films of known weight were kept in a desiccator (containing anhydrous calcium chloride) for a period of 4 days, after which they were taken out and then reweighed. Then, the percentage loss of moisture was calculated based on the difference in weight of the films (Baier et al., 1978, Rhim et al., 2006, Bumgardner et al., 2003).

\section{Uniformity in thickness of the films}

The thickness of the films was measured using thickness tester (Mitutoyo Corporation, MDC-25SB) at different positions of the films and finally the average thickness amongst them was calculated (Baier et al., 1978, Rhim et al., 2006, Bumgardner et al., 2003).

\section{Swelling Index}

Portion of the film $(6 \times 2 \mathrm{~mm})$ was cut its initial weight noted down and placed in the simulated gingival fluid $(\mathrm{pH} \mathrm{6.6)}$ at each interval of time it's taken out and re-weighed. This procedure is continued for the time period of 5 days. The purpose of this investigation is to find out the nature of formulation which will helps in correlation with the drug release studies (Baier et al., 1978, Rhim et al., 2006, Bumgardner et al., 2003).

\section{Water vapor transmission (WVT)}

The rate of WVT through the free films was determined as described by (King et al., 2005). For this a circular piece of film of known thickness was fixed with an adhesive over the top of the glass vial containing few a grams of fused calcium chloride as desiccant. The vial was weighed and kept in a desiccator maintained at $84 \%$ relative humidity (RH). The vial was taken out from the desiccator and weighed at regular time intervals for a period of 5 days. The experiment was carried in triplicate and the average values were calculated.

\section{Surface topography by using Scanning Electron Microscopy (SEM)}

Scanning electron microscope (Zeiss EVO-40 EP) was used to study the surface characters of the prepared and optimized film at accelerating voltage of $20.00 \mathrm{kV}$. Samples were mounted on the SEM sample slab using a double sided sticking tape. Samples were then coated with gold under reduced pressure $(0.001$ torr). Gold coated samples were then observed and suitable images were then taken (Kang et al., 2009). The lens used during investigation was Zeiss.

\section{In-vitro drug release by static method using diffusion cell}

As the film should be static in the periodontal cavity, therefore a static dissolution method is adopted for in vitro release process. Films of known amounts of LNC loaded were placed separately inside the donor compartment of the receiver cell sealed with aluminum foil, containing $5 \mathrm{ml}$ of simulated gingival fluid (pH 6.6) in the donor compartment of diffusion cell (Electrolab, EDC 07) and kept at $37^{\circ} \mathrm{C}$. In between cellophane semi permeable membrane which was previously preconditioned in the buffer. The sample was withdrawn $1 \mathrm{ml}$ with the help of calibrated syringe fitted with $0.45 \mu \mathrm{m}$ membrane after $2 \mathrm{hrs}$ and replaced with the freshly prepared simulated gingival fluid $\mathrm{pH}$ 6.6. Percentage drug release was calculated by using a UV spectrophotometer (Shimadzu UV 1800) at wavelength $212 \mathrm{~nm}$ which was previously validated. The procedure continued for the next 5 days.

\section{Ex-vivo flux study by static method using diffusion cell}

Ex-vivo tests were performed over 7 cell diffusion apparatus (Electrolab; EDC 07) having diffusion area of 2.009 $\mathrm{cm} 2$, for optimized formulation R2, R8, R11, R14, which are chosen on the basis of their in vitro test results as these formulation are designated as ER17, ER18, ER19 and ER20. The films were placed over the excised gum lining of the goat. The membrane of the skin surrounding the jaw was cut finely so that it covered the circular surface of the donor compartment. Then a small portion of the film $2 \mathrm{~cm}^{2}$ was kept in a donor compartment over the excised gum lining of goat and filled up to $5 \mathrm{ml}$ with simulated gingival fluid $\mathrm{pH}$ 6.6. The receiver compartment is also filled with the simulated gingival fluid $\mathrm{pH} 6.6$ and very low concentration $(0.002 \%)$ of gentamycin as an antibacterial agent. The temperature was set at $37^{\circ} \mathrm{C}$ to mimic the biological conditions. The sample was withdrawn $1 \mathrm{ml}$ with the help of calibrated syringe fitted with $0.45 \mu \mathrm{m}$ membrane after $2 \mathrm{hrs}$ and replaced with the freshly prepared simulated gingival fluid $\mathrm{pH} 6.6$ and average flux was calculated, using a UV spectrophotometer (Shimadzu UV 1800) at wavelength $212 \mathrm{~nm}$ which was previously validated.

\section{Curve fitting analysis and Akaike Information Criterion (AIC) value}

Different kinetic models such as zero order, first order, square root (Higuchi) can be applied to interpretation of drug release kinetics (Costa et al., 2001, Higuchi et al., 1961). A zeroorder release refers to a uniform or nearly uniform rate of release of a drug from the solid dosage form after coming in contact with an aqueous environment, independent of the drug concentration in the dosage form during a given time period. Dosage forms with zero order release generally provide maximum therapeutic value with minimum side effects (Korsmeyer et al., 1983). For many extended release formulations, the rate of drug release initially increases rapidly followed by decreased rate of drug release. This type of drug release is categorized as the first-order release. Such dosage form may not produce uniform concentration levels of the drug in the systemic circulation for a prolonged period of time. The Higuchi release equation (equation 1) predicts that the drug release is caused primarily by diffusion mechanism (Higuchi et al., 1961).

$$
\mathrm{Q}=\mathrm{K} V_{\mathrm{t}} \quad \text { Eqn. } 1
$$

Where, $\mathrm{Q}$ is the amount of the drug released in time $\mathrm{t}, \mathrm{K}$ is the release constant from the equation. The data were also subjected to Korsmeyer-Peppas power law (Korsmeyer et al., 1983) as in Equation 2. The Korsmeyer-Peppas model provides an insight into 
the type of drug release mechanism taking place from swellable polymeric matrices.

$$
\mathrm{Mt} / \mathrm{M} \infty=\mathrm{Kt}^{\mathrm{n}} \quad \text { Eqn. } 2
$$

Where $\mathrm{Mt} / \mathrm{M} \infty$ is the fraction of drug released in time $t, \mathrm{~K}$ is the structural and geometric constant, and $n$, the release exponent, is estimated from linear regression fit of the logarithmic release data. Intermediate $\mathrm{n}$ values indicate an anomalous behavior; that is, non Fickian kinetics corresponding to couple diffusion/polymer relaxation. In diffusion controlled systems, Fickian diffusion dominates the drug release process, whereas, in swelling controlled delivery systems; the rate of drug release depends on the swelling rate of polymer network (Korsmeyer et al., 1983, Ganjoo et al., 2013, Soni et al., 2016) Besides the $r^{2}$ values, the Akaike Information Criterion (AIC) were also used to test the applicability of the release models (Mendyk et al., 2012, Costa et al., 2001,). The Akaike Information Criterion is a measure of goodness of fit based on maximum likelihood. When comparing several models for a given set of data, the model associated with the smallest value of AIC is regarded as giving the best fit out of that set of models. The Akaike Criteria is only appropriate when comparing models using the same weight.

$$
A I C=n \times \ln (W S S R)+2 \times p \quad \text { Eqn. } 3
$$

Where, $\mathrm{n}$ is the number of dissolution data points $(\mathrm{M} / \mathrm{t}), \mathrm{p}$ is the number of the parameters of the model, WSSR is the weighted sum of square of residues, calculated by this process:

$$
W S S R=\sum_{r=l}^{n}\left[\mathrm{w}_{1}\left(\mathrm{y}_{1}-\mathrm{y}_{1}\right) 2\right] \quad \text { Eqn. } 4
$$

Where, $w$ is an optional weighing factor and $y$ denotes the predicted value of $y_{i}$. Table 3 depicts AIC values for various models calculated using KinetDS software (Mendyk et al., 2012).

\section{Statistical analysis}

The differences in average data were compared by simple analysis of variance (one-way analysis of variance) or Student's t test $\left(\right.$ SigmaPlot $\left.^{\circledR} 11\right)$.

\section{RESULTS AND DISCUSSION}

\section{Functional group characterization by FTIR}

FTIR spectra of (Figure 1 a) LNC represents the $\mathrm{C}=\mathrm{C}$ (aromatic) stretching at $1570 \mathrm{~cm}^{-1}, \mathrm{C}-\mathrm{H}$ (aliphatic) overtone at $2921.87 \mathrm{~cm}^{-1}, \mathrm{SCH}_{3}$ stretching at $1082.64 \mathrm{~cm}^{-1}, \mathrm{C}-\mathrm{C}$ (alpihatic) stretching at $1291.26 \mathrm{~cm}^{-1}$ and $\mathrm{C}-\mathrm{O}-\mathrm{C}$ (ether linkage) stretching at $1281.3 \mathrm{~cm}^{-1}$. FTIR spectra of (Figure $1 \mathrm{~b}$ ) MMWCH represents the $\mathrm{C}-\mathrm{H}$ (aliphatic) stretching at $2920 \mathrm{~cm}^{-1}, \mathrm{O}-\mathrm{H}$ (phenolic) stretching at $3290 \mathrm{~cm}^{-1}, \mathrm{CH}_{2}$ (aliphatic) stretching at $1384 \mathrm{~cm}^{-1}, \mathrm{C}-\mathrm{O}-\mathrm{C}$ (ether linkage) $1151 \mathrm{~cm}^{-1}$ and N-H (I) overtone at $3500-3300 \mathrm{~cm}^{-1}$.

FTIR spectra (Figure $2 \mathrm{c}$ ) Ethyl cellulose represents the $\mathrm{C}-\mathrm{H}$ (aliphatic) stretching at $2855 \mathrm{~cm}^{-1}, \mathrm{C}-\mathrm{O}-\mathrm{C}$ (ether linkage) at $1300 \mathrm{~cm}^{-1}, \mathrm{O}-\mathrm{H}$ (phenolic) stretching at $3300 \mathrm{~cm}^{-1}, \mathrm{C}-\mathrm{C}$ (aromatic) at $1520 \mathrm{~cm}^{-1}$ and $\mathrm{C}-\mathrm{O}$ (stretching) at $1200 \mathrm{~cm}^{-1}$ respectively. Apart from these when pure $\mathrm{LNC}, \mathrm{MMWCH}, \mathrm{EC}$ used in combination in the ratio of (1:1:1) it shows the spectra (Figure $2 \mathrm{~d}$ ) $\mathrm{C}-\mathrm{H}$ (aliphatic) stretching at $2877 \mathrm{~cm}^{-1}, \mathrm{O}-\mathrm{H}$ (phenolic) stretching at $3357 \mathrm{~cm}^{-1}$, $\mathrm{CH}_{2}$ (aliphatic) stretching at $1544 \mathrm{~cm}^{-1}$ and $\mathrm{C}-\mathrm{O}-\mathrm{C}$ (ether linkage) stretching at $1153 \mathrm{~cm}^{-1}$ respectively. From all these spectra obtained we can conclude that there is no any change or shifting in the major characteristic peaks in the formulation, in drug and polymers when used in combination or in alone and this study indicates that there is no any drug-polymer interaction takes place.
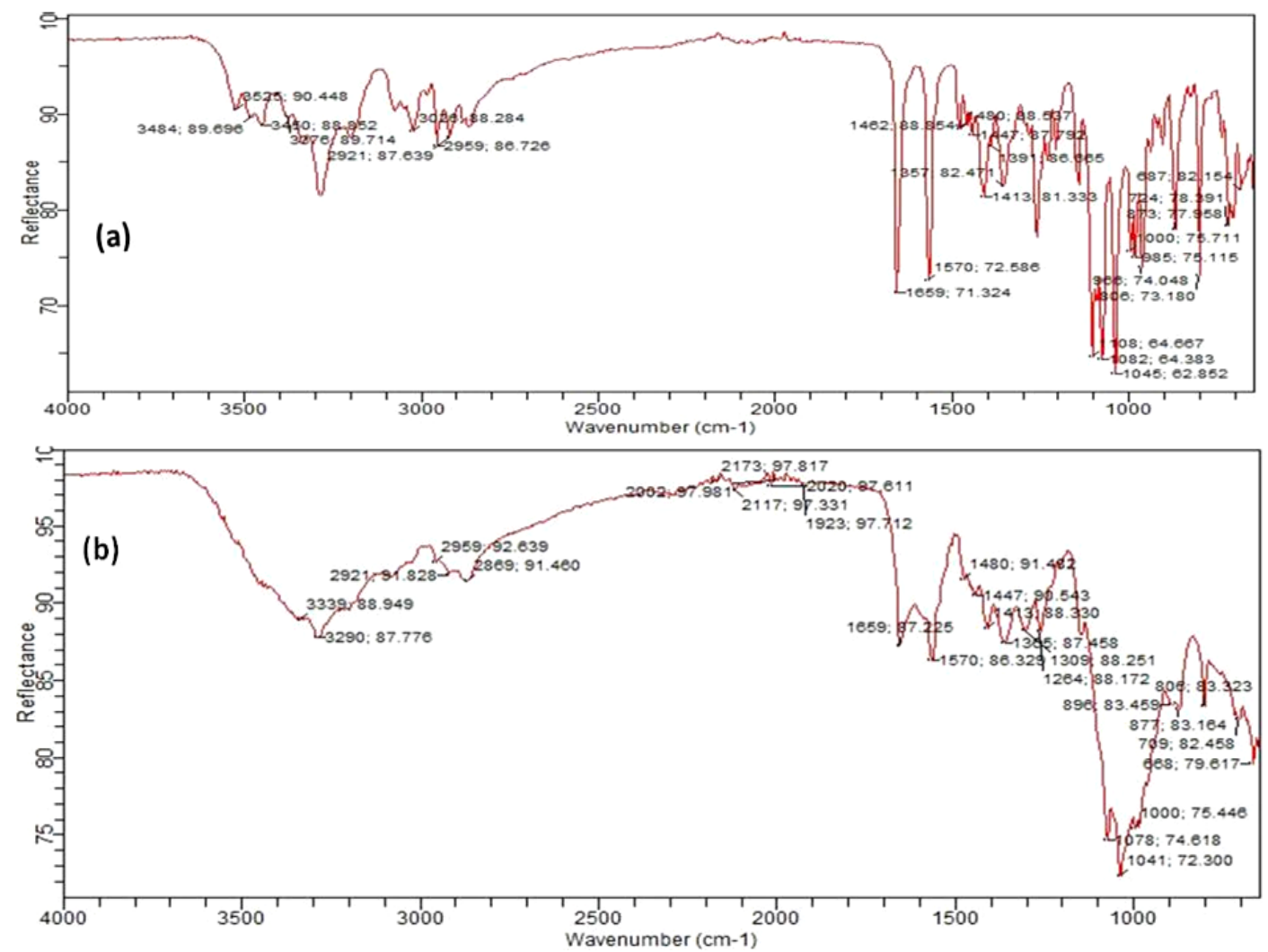

Fig. 1: FTIR spectra of (a) Lincomycin Hydrochloride; LNC (b) Medium Molecular Weight Chitosan; MMWCH. 

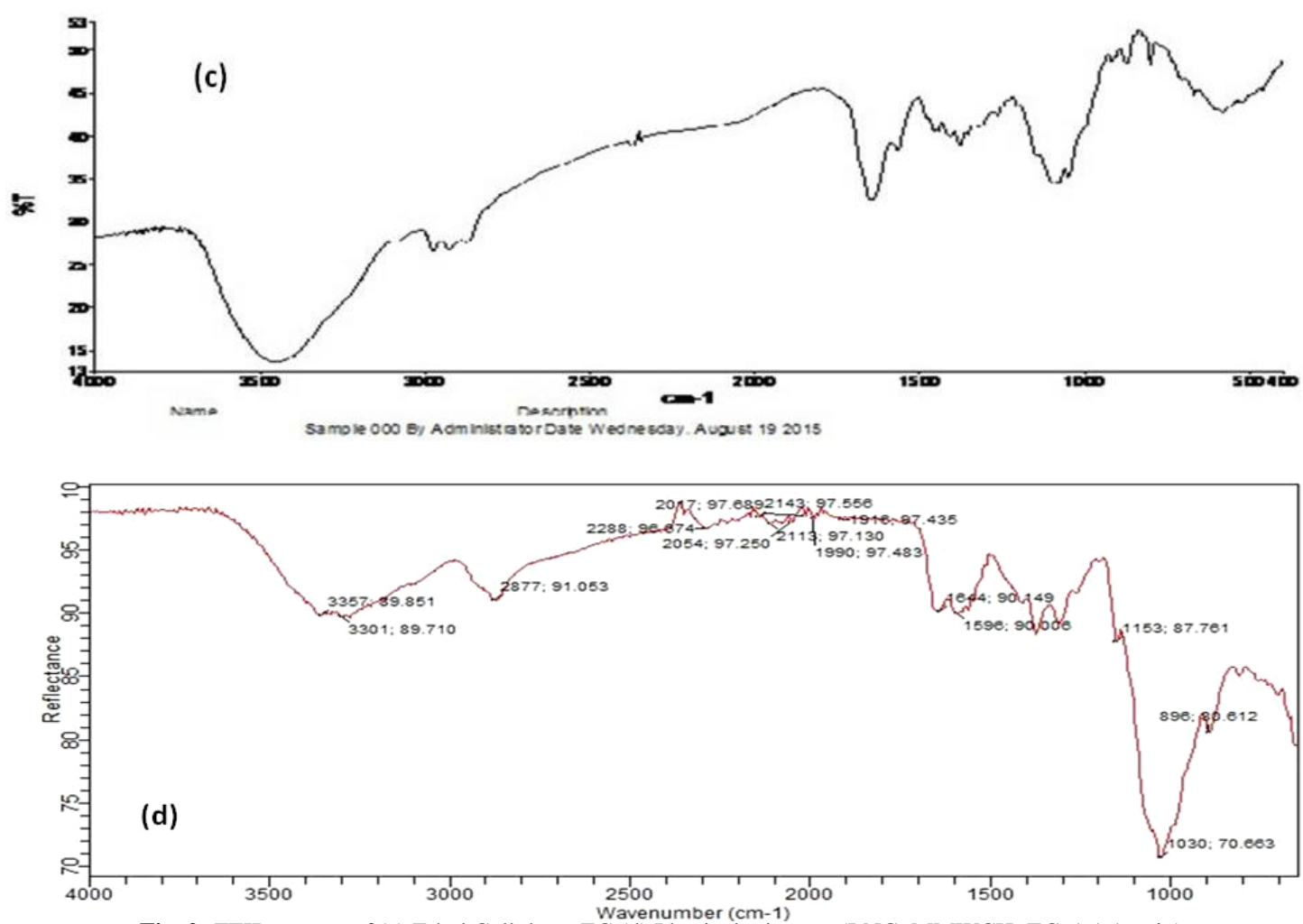

Fig. 2: FTIR spectra of (c) Ethyl Cellulose; EC (d) Physical mixtures (LNC: MMWCH: EC, 1:1:1 ratio).

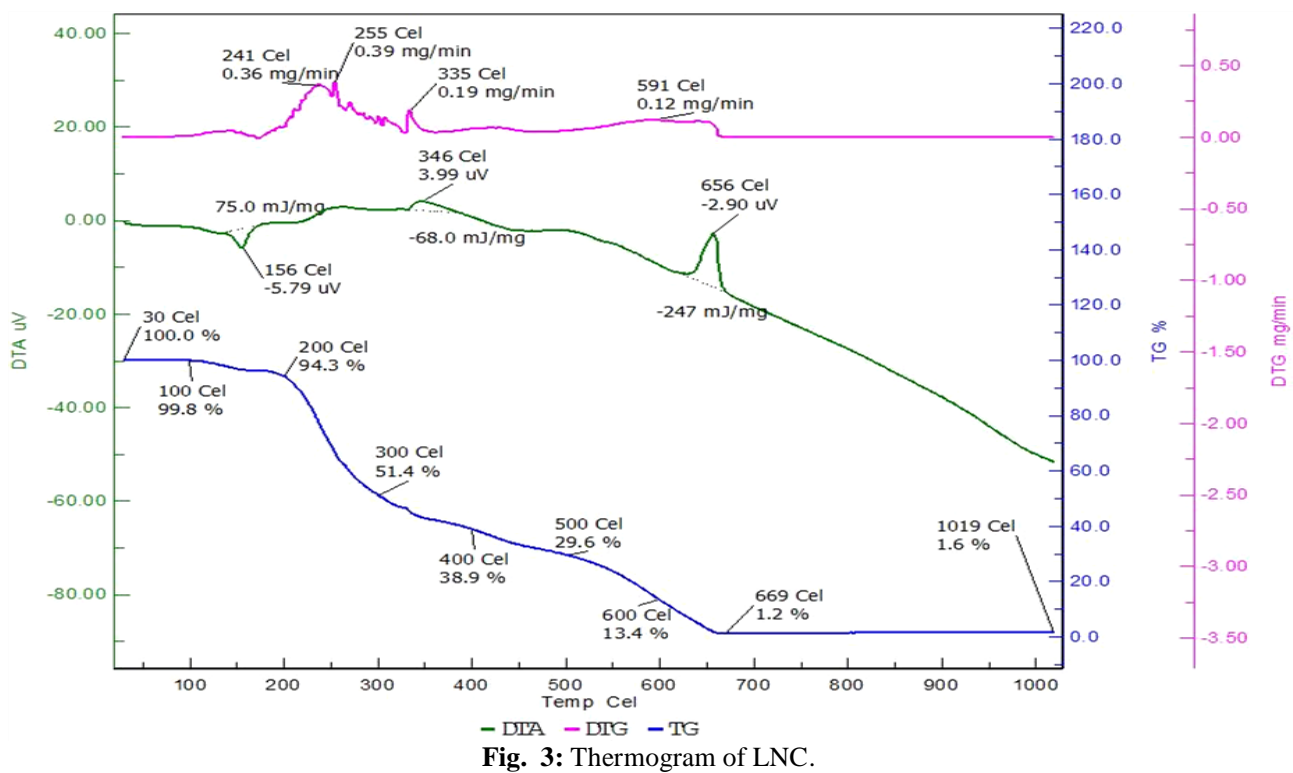

\section{Thermo analytical characterization}

Figure 3 represents the thermogram of the LNC. DTG thermogram explains that the drug is stable up to $255^{\circ} \mathrm{C}$ and degradation of the drug are in one stage process. Maximum loss of mass occurs at temperatures ranging between $200-300{ }^{\circ} \mathrm{C}(\%$ decrease in mass is about $48.5 \%$ ) indicated by TGA thermogram. The DTA thermogram of the LNC shows one sharp and broad endothermic peak at $156{ }^{\circ} \mathrm{C}$ (enthalpy $75.0 \mathrm{mJoule} / \mathrm{mg}$ ) which reveals the melting point. Also, there is the presence of two broad exothermic peak at $346^{\circ} \mathrm{C}$ and $656^{\circ} \mathrm{C}$ (enthalpy $-68.0 \mathrm{mJoule} / \mathrm{mg}$ and $-247 \mathrm{mJoule} / \mathrm{mg}$ respectively) representing crystallization (glass transition) and slow decomposition of drug respectively.

Figure 4 represents thermogram of MMWCH. DTG thermogram shows that there is very small exothermic peak at $77^{\circ} \mathrm{C}$ which represents the vaporization of water molecules from the void spaces and the surface of MMWCH and another exothermic peak at $295^{\circ} \mathrm{C}$ represents that the MMWCH is stable up to a temperature of $295^{\circ} \mathrm{C}$. 


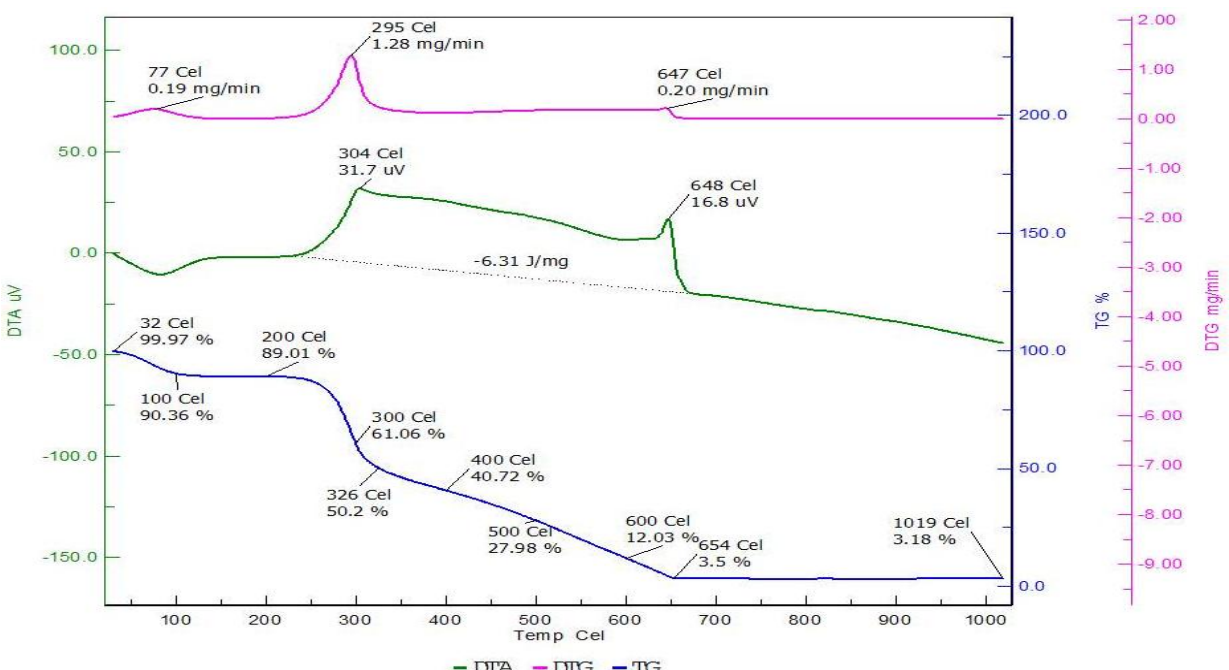

Fig. 4: Thermogram of MMWCH.

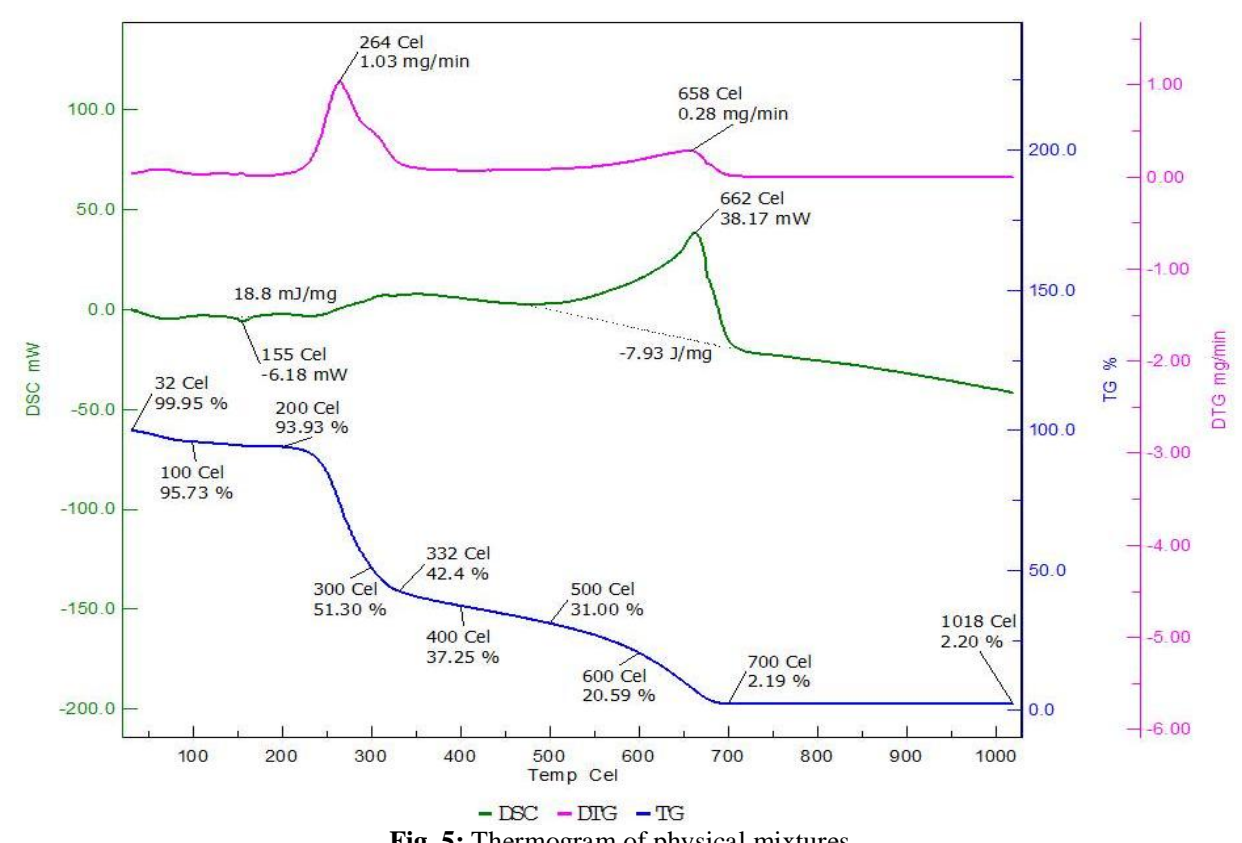

Fig. 5: Thermogram of physical mixtures.

DTA thermogram of MMWCH represents broad exothermic peak at $304^{\circ} \mathrm{C}$ (enthalpy $-6.31 \mathrm{Joule} / \mathrm{mg}$ ) representing slow thermal degradation. Degradation and maximum loss of water molecules is represented by the TGA thermogram as shown by the biphasic curves. There is the maximum loss of water molecules and decrease in mass up to $38.4 \%$. Figure 5 represents the thermogram of physical mixtures. DTG thermogram explains, the drug is stable up to the temperature of $264^{\circ} \mathrm{C}$ and another broad exothermic peak represents the polymers (Chitosan, ethyl cellulose), which are stable up to $658^{\circ} \mathrm{C}$. Maximum loss of mass occurs at temperature 200-3000C. DTA thermogram explains the presence of small endothermic peak at $155^{\circ} \mathrm{C}$ (enthalpy 18.8 $\mathrm{mJoule} / \mathrm{mg}$ ), which in turn represents the melting point of drug, presence of exothermic peak at $662{ }^{\circ} \mathrm{C}$ (enthalpy -7.93 Joule/mg), which represents the slow degradation of the formulation.
TGA thermogram shows the maximum loss of mass from the physical mixture takes place from $200-300{ }^{\circ} \mathrm{C}$ about $51.30 \%$, this is attributed due to the loss of bound and unbound water molecules from the surface of mixtures. All the characteristics peaks are present in drug and excipient, through this we can divulge that there is no drug excipient interaction occurs between drug, excipient and drug excipient mixture.

\section{Evaluation Parameters}

The present study was an attempt to develop intra-pocket dental film, which is fabricated with polymers. The formulation developed was a matrix system which had better physicochemical properties, release profile in simulated gingival fluid $\mathrm{pH}$ 6.6. The films were $5.5-6.0 \mathrm{~cm}$ in diameter. Percent drug content uniformity of the patches ranges from $90.58 \pm 0.14-99.94 \pm 0.12$ from this we 
can say that the maximum amount of drug is loaded in the patches. Surface $\mathrm{pH}$ of the patch was found to be neutral i.e. $\mathrm{pH}$ 6. If the $\mathrm{pH}$ found acidic or basic it can lead to the irritation in the gum lining so its study is an important parameter. No significant difference in $\mathrm{pH}$ was observed. Weight uniformity of all the patches is $20.1 \mathrm{mg} \pm 0.21 ; \mathrm{n}=3$ which ranges from $19.9 \mathrm{mg}$ to 20.1 mg. Folding endurance ranges from 98 folds to 129 folds at the same point, this test suggests that the prepared patches have the best mechanical strength. The Water Vapor Transmission Rates (WVTR) of MMWCH and EC films suggests that as the thickness of the films increases the WVT rate also increases due to the difference in the concentration of drug and polymer and film is permeable to water vapour and it ranges from $1.670 \times 10^{-4}-1.123 \times 10^{-4}$ The $\%$ moisture loss from the film ranges from $9.33 \pm 0.10$ to $21.86 \pm 0.15$ having low standard deviations which means the film is stable. The \% swelling index is the important tool to study the nature of the formulation before dissolution studies. \% swelling index varies from $27.8 \pm 0.17$ to $49.7 \pm 0.13$. Swelling index depends on the nature of polymers, whether they are water soluble or not. Swelling can increase the surface area of the patches and the diffusion path length of the drug which directly delay the release of the drug. All the above parameters are depicted in table 2 .

\section{Surface Topography Studies}

Surface topography studies using SEM at various magnifications are shown in fig. 6. Carried study indicates that at (Figure $6 \mathrm{a}, \mathrm{b}$ ) 500x and 1000x particles of LNC clearly seen in the transverse section which means that the LNC is not completely soluble in the polymer that's why during the static in vitro release studies it shows the initial burst release during first two hours of study $(24.12 \%)$. In figure (Figure $6 \mathrm{c}, \mathrm{d}$ ) the LNC crystals are

Table 2: Table showing different Evaluation Parameter.

\begin{tabular}{|c|c|c|c|c|c|c|c|c|}
\hline $\begin{array}{l}\text { Formulation } \\
\text { code }\end{array}$ & $\begin{array}{l}\% \text { Content } \\
\text { uniformity }\end{array}$ & $\begin{array}{l}\text { \% Drug washed } \\
\text { after washing } \\
\text { with } 0.1 \mathrm{M} \\
\text { Glycine } \\
\end{array}$ & $\begin{array}{c}\text { Weight } \\
\text { Uniformity } \\
\text { (mg) }\end{array}$ & $\begin{array}{l}\text { Thickness of } \\
\text { the film (mm) }\end{array}$ & $\begin{array}{c}\text { Surface } \\
\text { pH }\end{array}$ & $\%$ Moisture loss & $\begin{array}{l}\text { \% Swelling } \\
\text { index }\end{array}$ & $\begin{array}{c}\text { WVTR } \\
\underset{\text { days })}{\left(\mathrm{gm} . \mathrm{cm} / \mathrm{cm}^{2} .5\right.}\end{array}$ \\
\hline R1 & $99.90 \pm 0.12$ & - & $19.80 \pm 0.67$ & $0.56 \pm 0.11$ & $6.0 \pm 0.11$ & $15.85 \pm 0.12$ & $49.17 \pm 0.13$ & $1.131 \times 10^{-4}$ \\
\hline $\mathrm{R} 2$ & $98.10 \pm 0.12$ & - & $19.21 \pm 0.98$ & $0.61 \pm 0.17$ & $6.0 \pm 0.11$ & $21.86 \pm 0.15$ & $27.18 \pm 0.17$ & $1.137 \times 10^{-4}$ \\
\hline R3 & $99.20 \pm 0.23$ & - & $19.82 \pm 0.34$ & $0.58 \pm 0.11$ & $6.0 \pm 0.14$ & $20.12 \pm 0.13$ & $35.96 \pm 0.11$ & $1.123 \times 10^{-4}$ \\
\hline $\mathrm{R} 4$ & $98.20 \pm 0.23$ & - & $19.91 \pm 0.65$ & $0.60 \pm 0.15$ & $6.0 \pm 0.16$ & $15.01 \pm 0.11$ & $35.56 \pm 0.12$ & $1.135 \times 10^{-4}$ \\
\hline R5 & $91.47 \pm 0.23$ & $5.90 \pm 054$ & $19.21 \pm 0.35$ & $0.61 \pm 0.16$ & $6.0 \pm 0.11$ & $18.22 \pm 0.12$ & $27.50 \pm 0.17$ & $1.137 \times 10^{-4}$ \\
\hline R6 & $90.58 \pm 0.14$ & $3.11 \pm 0.56$ & $19.31 \pm 0.13$ & $0.58 \pm 0.10$ & $6.0 \pm 0.18$ & $9.33 \pm 0.10$ & $37.51 \pm 0.14$ & $1.399 \times 10^{-4}$ \\
\hline R7 & $97.12 \pm 034$ & $2.37 \pm 0.60$ & $20.11 \pm 0.42$ & $0.60 \pm 0.11$ & $6.0 \pm 0.11$ & $12.22 \pm 0.11$ & $38.54 \pm 0.11$ & $1.342 \times 10^{-4}$ \\
\hline $\mathrm{R} 8$ & $93.14 \pm 0.56$ & $5.41 \pm 0.34$ & $19.90 \pm 0.21$ & $0.56 \pm 0.13$ & $6.0 \pm 0.17$ & $11.70 \pm 0.11$ & $36.25 \pm 0.15$ & $1.356 \times 10^{-4}$ \\
\hline R9 & $94.11 \pm 0.43$ & $8.53 \pm 0.09$ & $20.10 \pm 0.11$ & $0.57 \pm 0.16$ & $6.0 \pm 0.11$ & $11.67 \pm 0.11$ & $37.34 \pm 0.15$ & $1.450 \times 10^{-4}$ \\
\hline $\mathrm{R} 10$ & $96.89 \pm 0.54$ & $9.42 \pm 0.31$ & $20.20 \pm 0.09$ & $0.63 \pm 0.11$ & $6.0 \pm 0.11$ & $12.86 \pm 0.14$ & $36.69 \pm 0.16$ & $1.189 \times 10^{-4}$ \\
\hline R11 & $97.63 \pm 0.23$ & $2.88 \pm 0.02$ & $19.19 \pm 0.32$ & $0.67 \pm 0.11$ & $6.0 \pm 0.15$ & $13.01 \pm 0.12$ & $37.02 \pm 0.11$ & $1.451 \times 10^{-4}$ \\
\hline $\mathrm{R} 12$ & $94.59 \pm 0.61$ & $6.86 \pm 0.06$ & $19.11 \pm 0.65$ & $0.61 \pm 0.17$ & $6.0 \pm 0.11$ & $10.26 \pm 0.15$ & $34.90 \pm 0.11$ & $1.670 \times 10^{-4}$ \\
\hline $\mathrm{R} 13$ & $99.80 \pm 0.45$ & - & $20.21 \pm 0.21$ & $0.59 \pm 0.11$ & $6.0 \pm 0.13$ & $11.45 \pm 0.16$ & $37.63 \pm 0.17$ & $1.281 \times 10^{-4}$ \\
\hline R14 & $99.61 \pm 0.67$ & - & $19.31 \pm 0.21$ & $0.62 \pm 0.18$ & $6.0 \pm 0.11$ & $9.06 \pm 0.107$ & $30.02 \pm 0.11$ & $1.274 \times 10^{-4}$ \\
\hline $\mathrm{R} 15$ & $98.78 \pm 0.89$ & - & $19.50 \pm 0.81$ & $0.58 \pm 0.13$ & $6.0 \pm 0.12$ & $13.98 \pm 0.12$ & $38.11 \pm 0.10$ & $1.341 \times 10^{-4}$ \\
\hline $\mathrm{R} 16$ & $98.40 \pm 0.42$ & - & $19.60 \pm 098$ & $0.57 \pm 0.11$ & $6.0 \pm 0.11$ & $12.11 \pm 0.10$ & $35.92 \pm 0.11$ & $1.367 \times 10^{-4}$ \\
\hline
\end{tabular}

All the experiment were performed in triplicate and data are expressed as Mean \pm S.D.
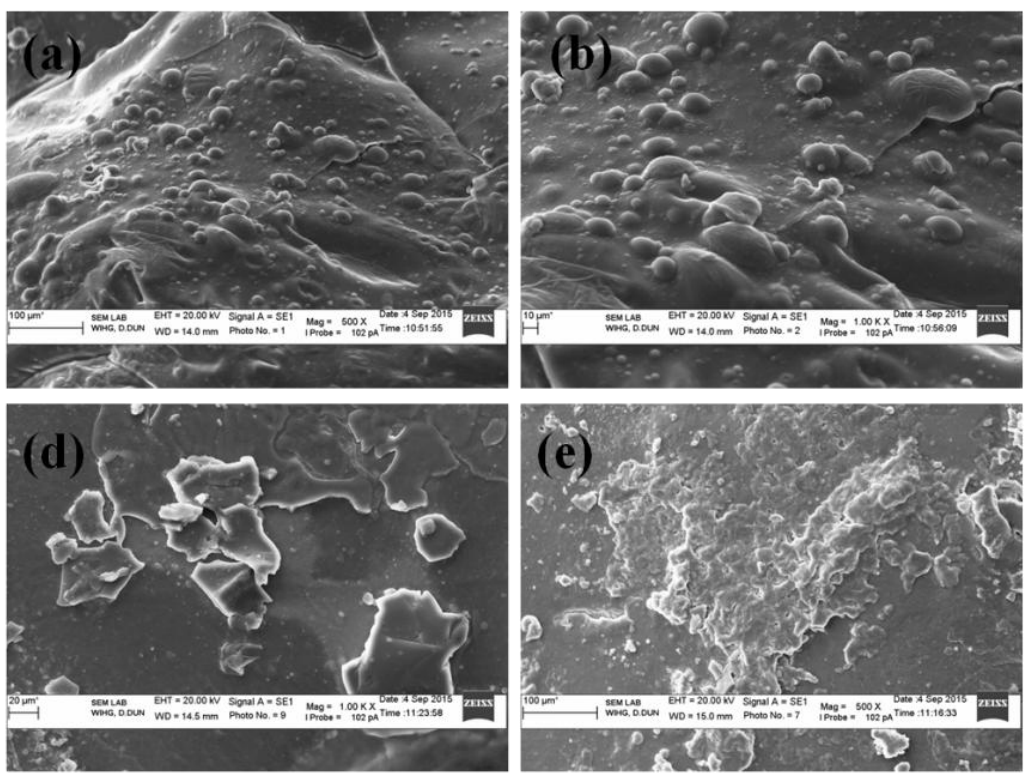

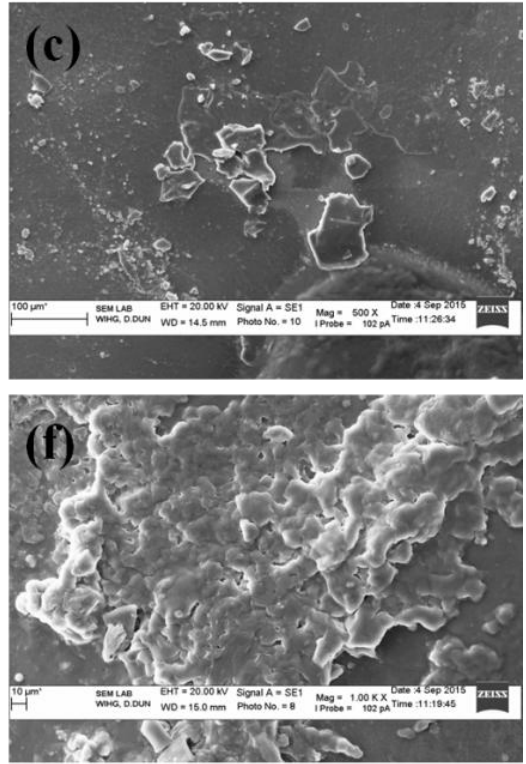



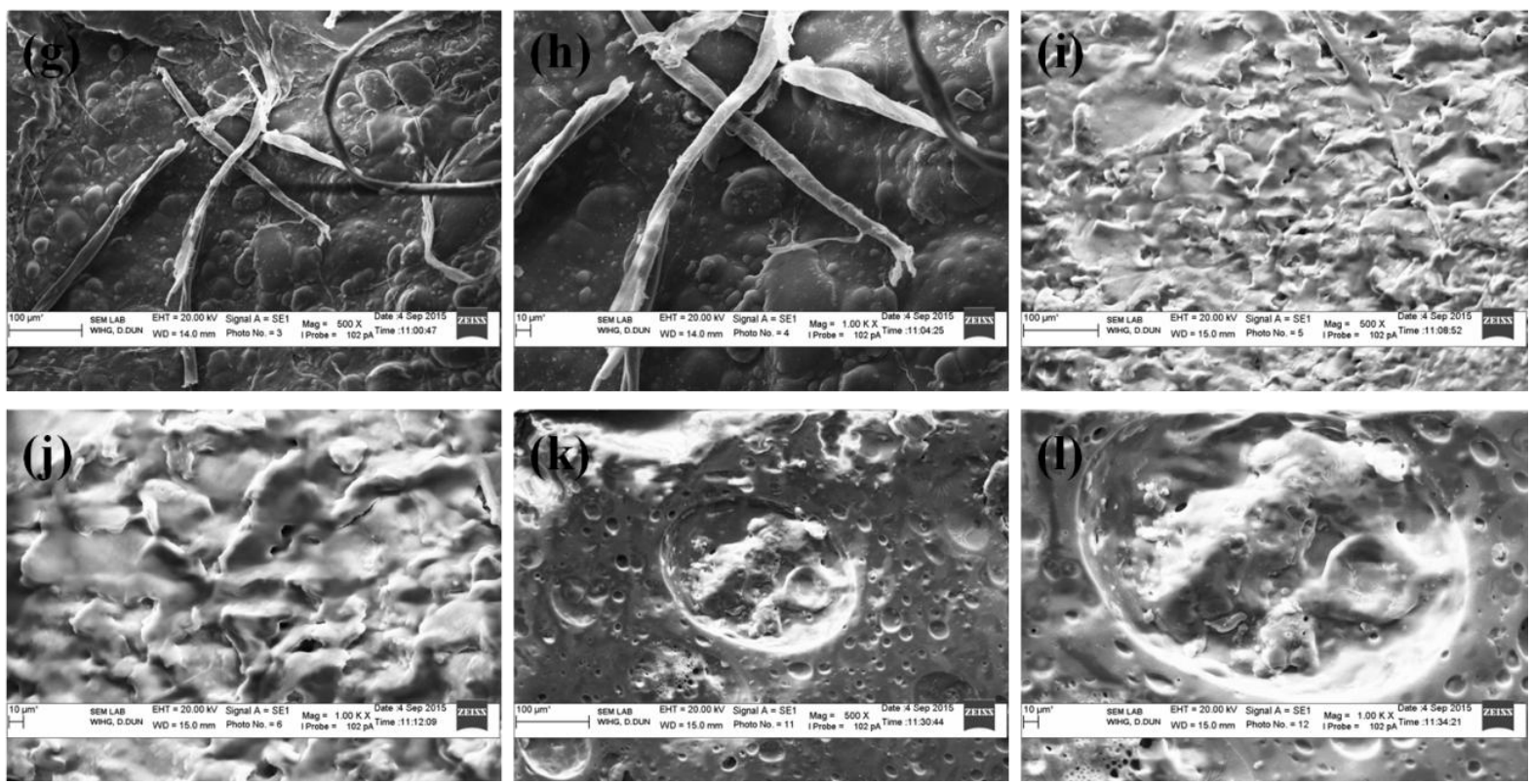

Fig. 6: Surface topography study of dental patches using SEM (a) Transverse section at 500x (b) Transverse section at 1000x (c) Direct cross linked patch with glutraldehyde at 500x before dissolution studies (d) Direct cross linked patch with glutraldehyde at 1000x before dissolution studies (e) Direct cross linked patch with glutraldehyde at 500x after dissolution studies (f) Direct cross linked patch with glutraldehyde at 1000x after dissolution studies (g) Indirect cross linked patch with glutraldehyde at 500x before dissolution studies (h) Indirect cross linked patch with glutraldehyde at 1000x before dissolution studies (i) Indirect cross linked patch with glutraldehyde at 500x after dissolution studies (j) Indirect cross linked patch with glutraldehyde at 1000x after dissolution studies (k) Release liners of HPMC at 500x (1) Release liners of HPMC at 500x

present in small clusters due to insolubility of LNC when studied at 500x and 1000x before dissolution studies.

After 5 days dissolution studies, it was observed that the there is surface erosion of the polymers and formation of small vacuoles (Figure $6 \mathrm{ef}$ ), the possible reason behind this is due to the continuous penetration of dissolution media which causes the surface erosion and it not hold the LNC for longer period of time as from the dissolution studies we can correlate for formulation (R5-R7) at the last 4 hours it shows the somewhat fast release of LNC from the polymer matrices due to the erosion of polymer which not helps in sustaining of LNC. (Figure $6 \mathrm{~g}$, h) represents the surface morphology of MMWCH films when indirectly treated with glutraldehyde. From obtained SEM images we can say that the indirect use of glutraldehyde not causes the sufficient cross linking of polymers and strands of MMWCH clearly seen at 500x and 1000x. But after static dissolution studies for 5 days this MMWCH strand dissolves (Figure $6 \mathrm{i}, \mathrm{j}$ ) due to its solubility and matrix surface bearing polymers become erode and not hold the LNC for longer period this can be correlated with the static drug release studies for formulation R9, R11, R12 which in last few hours shows the irregular pattern of drug release. (Figure $6 \mathrm{k}, \mathrm{l}$ ) represents the surface topography of HPMC release liners at 500x and 1000x respectively indicating the surface is smooth and cross linked which would retains the LNC inside for longer period of time.

\section{In-vitro drug release by static method using diffusion cell}

Static in-vitro drug release studies were performed using diffusion cell (Electrolab; EDC-07), the obtained results for formulation R1-R4 shows the drug release of $88.28 \%, 92.25 \%$, $92.09 \%$ and $87.32 \%$ respectively for a period of five days. This is attributed due to nature of polymers used. For the formulation R1$\mathrm{R} 4$ there is a rapid release of LNC from the surface of the patch as the time increases this rapid burst of release changes to the sustained release as seen in figure 7 a. This type of behavior is due to either LNC is present on the surface of a patch which causes its release into the medium when it comes to contact with after that MMWCH or EC acts as a retarding polymer which retards the release of the LNC. The above prepared films are made up by the help of a solvent casting technique. Formulations R5-R8 are significantly different from R1-R4, $p=0.05$. These films were prepared by direct cross linking with glutraldehyde. The reason for choosing glutraldehyde is to cross link the matrices of $\mathrm{MMWCH}$, then the patch is washed with $0.1 \mathrm{M}$ glycine solution to remove the unreacted traces of glutraldehyde from the matrices. Formulation R5-R8 shows the drug release of $94.1 \%, 96.89 \%, 97.63 \%$ and $94.59 \%$ respectively for a period of five days (figure $7 \mathrm{~b}$ ). The intent of incorporating EC was to modify the hydrophilicity of the polymer matrix. The invariant release pattern observed due to the large density difference between LNC and EC particles. When the formulation was exposed to dissolution media, EC acted as a barrier and only LNC present on the surface of patch goes to dissolution media. This hydrophobic EC acts as a barrier for retardation and as the $\mathrm{EC}$ removes out from the formulations MMWCH acts as retard barrier which helps in the retardation of LNC for five days. Formulation R9-R12 are significantly different from R1-R4 and R5-R8, $p=0.05$. These films were prepared by indirect cross linking with saturated fumes of glutraldehyde in the 
A

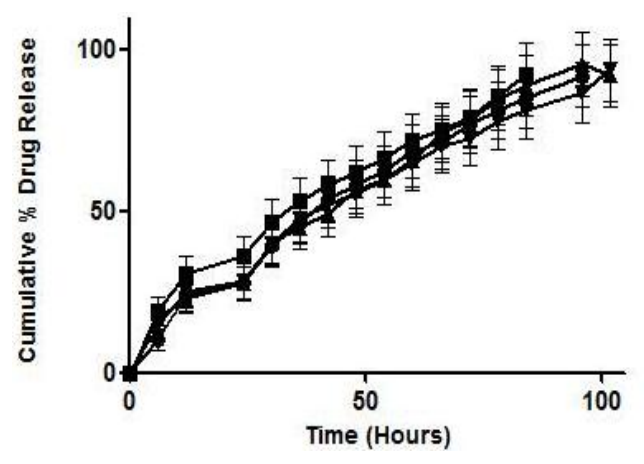

C

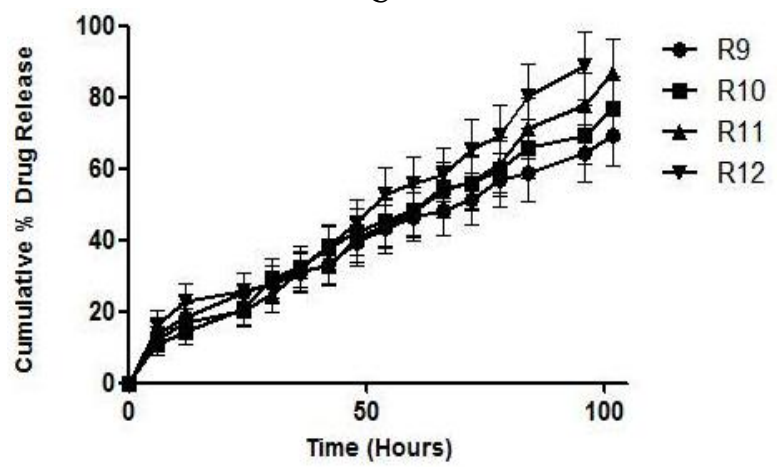

B

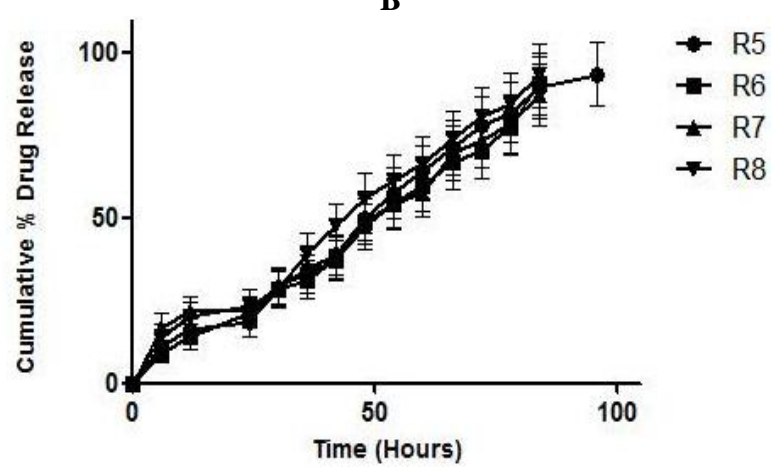

D

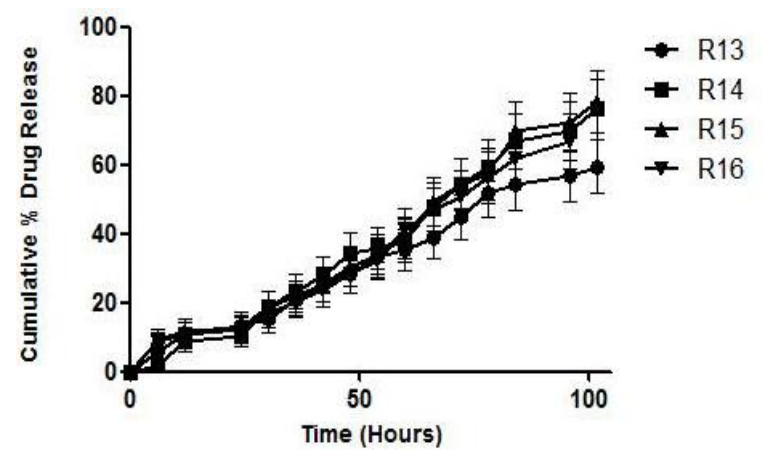

Fig. 7: Static in vitro release studies of LNC patches in SGF pH 6.6 by using diffusion cell

chamber. It shows the drug release of $91.47 \%, 90.58 \%, 97.12 \%$, and $93.14 \%$ respectively for five days (figure $7 \mathrm{c}$ ). The possible reason for drug release pattern is depend on the hydrophobic nature of EC and indirect fumes of glutraldehyde which not cross linked the MMWCH as much which seen in R5-R8 formulations. Formulation R13-R16 shows the significantly difference from R1$\mathrm{R} 4$ and $\mathrm{R} 5-\mathrm{R} 8, p=0.05$. The films were prepared by using HPMC as release liners and a mixture of LNC with MMWCH and EC were filled in to liners. It shows the drug release of $98.53 \%$, $96.22 \%, 98.06 \%$ and $96.86 \%$ respectively (figure $7 \mathrm{~d}$ ), in this EC was replaced with HPMC. When HPMC comes in contact with the dissolution media it forms a glassy polymeric structure which is rate limiting step for the sustaining of the drug from the patch matrices, and inside glassy structure, there is mixture of LNC with MMWCH and EC which releases out from matrixes in a sustained manner.

\section{Ex-vivo flux study using diffusion cell}

Now a day's Chitosan is attracting lots of focus on scientist due to its nontoxicity, biodegradability, and better bio compatibility behavior. High molecular weight Chitosan (HMWCH; physically/chemically modified forms) is found to be good carriers for enhancing the permeability rate. High molecular weight and its solubility in water or organic compound do not help in interacting with the under layers of skin surface and significantly blocks the enhancement effect. (Zhou et al., 2010); reported the effectiveness of Low molecular weight Chitosan
(LMWCH) on drug permeation through mouse skin due to its superior biological activities. There is no work attempt on MWCH for permeation studies till date. Hence we selected dental patch formulation based on MMWCH and its effect on flux over the excised gum lining of goat. MMWCH is co-polymer of Nacetyl-D-glucosamine and D-glucosamine, which is dependent on the degree of deacetylation. From the biopharmaceutical point of view, it is reported that this polymer has excellent characteristics of mucoadhesion and enhancement of paracellular transportation, though opening of tight juncture between epithelial cells. In this our study, we studied the effect of EC and MMWCH on the permeation rate of the $\mathrm{LNC}$.

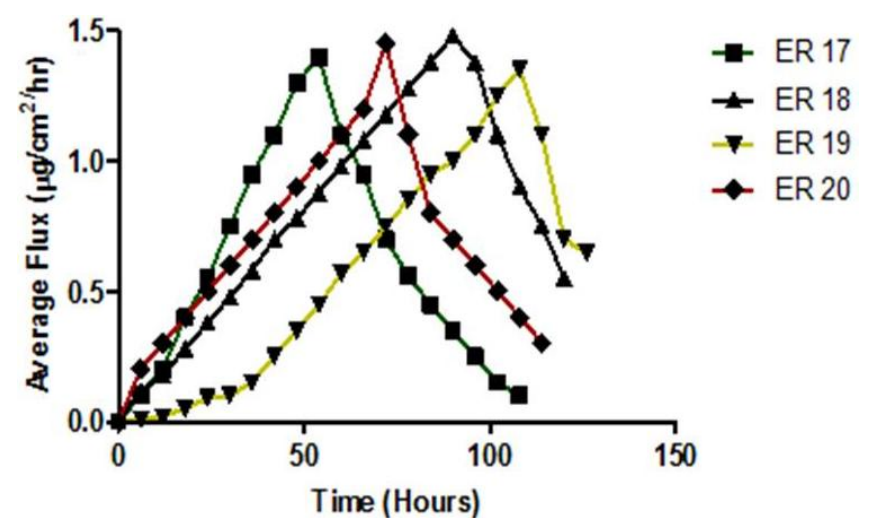

Fig. 8: Representing average fluxes through gum lining of goat $v s$. time. 
This EC creates a hydrophobic environment and increases the hydrophilicity of the formulation. The whole skin structure has an isoelectric point of 4-4.5. The carboxylic acid group of subcutaneous i.e. intracorneocyte keratin and intercorneocyte glycoprotein can may interact with the copolymer group of $\mathrm{MMWCH}$ at $\mathrm{pH} 6.6$ and affect the average flux rate (figure 8). Formulation (ER17, ER18, ER19 and ER20) is having the average flux of $1.0,1.48,1.35$ and $1.45 \mathrm{mg} / \mathrm{cm}^{2} / \mathrm{hr}$ respectively and when compared statistically student's paired t-test these all formulations are significantly different from each other $(p=0.05)$. The highest average flux was found in E20 in which EC used is $300 \mathrm{mg}$ (figure 8). As the amount of EC increases the average flux decreases due to its hydrophobic nature and oligomer N-acetyl-Dglucosamine and D-glucosamine plays a vital role in the transportation of drug in the membrane structure to the specific targeted sites.

\section{Release Kinetics and AIC value}

When the curve fitting analysis and AIC value determined using Kinet DS software we find that formulation R1, R2, R7, R8, R9, R10, R13 and R14 follows the zero order release pattern which implies that the release pattern is not depend on the LNC but it is based on the polymer which helps in the retardation of it. Formulation R3, R4, R5, R6, R11, R12, R15 and R16 follow the Higuchi model which means that the LNC release is from diffusion mechanism i.e. higher concentration from the patch to the lower concentration of SGF ( $\mathrm{pH}$ 6.6). Besides $\mathrm{r}^{2}$ value AIC value was also determined to test the applicability of kinetics model. Formulation R1, R2, R7, R8, R9, R10, R13 and R14 and follows the zero order release pattern and formulation R3, R4, R5, R6, R11, R12, R15 and R16 follows the Higuchi model because they have the lower AIC value. All these values are depicted in table 3.

Table 3: Release Kinetics and AIC value.

\begin{tabular}{ccccccc}
\hline \multirow{2}{*}{$\begin{array}{c}\text { Formulation } \\
\text { Code }\end{array}$} & $\begin{array}{c}\text { Zero } \\
\text { order }\end{array}$ & $\begin{array}{c}\text { First } \\
\text { order }\end{array}$ & $\begin{array}{c}\text { Higuchi } \\
\text { model }\end{array}$ & $\begin{array}{c}\text { Zero } \\
\text { order }\end{array}$ & $\begin{array}{c}\text { First } \\
\text { order }\end{array}$ & $\begin{array}{c}\text { Higuchi } \\
\text { model }\end{array}$ \\
\hline R1 & 0.9998 & 0.9627 & 0.9954 & 88.179 & 92.121 & 153.801 \\
R2 & 0.9990 & 0.8670 & 0.9330 & 84.372 & 107.452 & 143.561 \\
R3 & 0.9871 & 0.9275 & 0.9912 & 170.742 & 105.899 & 102.310 \\
R4 & 0.9728 & 0.7273 & 0.9932 & 179.321 & 112.894 & 90.812 \\
R5 & 0.9861 & 0.8276 & 0.9924 & 81.779 & 99.672 & 54.110 \\
R6 & 0.9896 & 0.9296 & 0.9988 & 169.612 & 116.892 & 102.960 \\
R7 & 0.9994 & 0.8280 & 0.9857 & 82.832 & 118.329 & 140.442 \\
R8 & 0.9971 & 0.9286 & 0.9889 & 72.492 & 115.732 & 143.431 \\
R9 & 0.9998 & 0.8257 & 0.9897 & 72.190 & 105.67 & 141.272 \\
R10 & 0.9991 & 0.8269 & 0.9899 & 65.432 & 118.78 & 144.422 \\
R11 & 0.9832 & 0.9269 & 0.9986 & 175.512 & 128.892 & 105.541 \\
R12 & 0.9744 & 0.8264 & 0.9904 & 105.419 & 123.762 & 99.292 \\
R13 & 0.9915 & 0.9261 & 0.8761 & 81.122 & 134.765 & 139.122 \\
R14 & 0.9947 & 0.9316 & 0.8669 & 75.893 & 167.894 & 145.301 \\
R15 & 0.9780 & 0.9275 & 0.9781 & 188.301 & 172.762 & 154.262 \\
R16 & 0.9782 & 0.9275 & 0.9881 & 88.342 & 118.873 & 54.268 \\
\hline
\end{tabular}

\section{CONCLUSION}

In this research work, a novel effort was made to design a dental film loaded with drug LNC fabricated with polymers for a disease periodontitis. The main purpose of formulating film was to extend the drug release for a longer period of time and the main advantage of this research work is to minimize the frequent dosing of drug as in case of conventional formulation which leads to better patient compliance. On the basis of thorough and regular study of review of literature and research work regarding LNC, no previous attempts have been made to formulate dental films with LNC to cure the disease periodontitis. Dental films containing LNC and MMWCH with co-polymers were designed. The patch shows the portion of LNC was physically dispersed into the polymeric chains of $\mathrm{MMWCH}$ in crystal form. Drug and polymer did not interact chemically; inducing the uptake of water into the polymeric chain due to the penetration of the medium was related to the formation of $\mathrm{H}$ - bonds between water and $\mathrm{O}-\mathrm{H}$ and $\mathrm{N}-\mathrm{H}$ group of MMWCH which leads to gel formation, which controlled the LNC release from the colloidal sol matrices. The release pattern also revealed that the absence of the initial burst of the drug. The obtained results suggest that LNC loaded MMWCH patches could be alternative for the treatment and site specific delivery, as compared to gel, pastes and other dosages forms which offer site specific pharmacological therapy, improved bioavailability and suppress the toxicity. Authors also plan to study the effect of developed system in patients after obtaining permission from ethical committee.

\section{ACKNOWLEDGEMENT}

Authors are thankful to Sardar Bhagwan Singh PG Institute of Biomedical Sciences and Research, Dehradun, India. Authors are also thankful to Indian Institute of Technology, Roorkee and Wadia Institute of Himalyan Geology, Dehradun, India for characterization of samples.

\section{Financial support and sponsorship: Nil.}

Conflict of Interests: There are no conflicts of interest.

\section{REFERENCES}

Ahmed MG, Harish NM, Charyulu RN, and Prabhu, P. Formulation of chitosan-based ciprofloxacin and diclofenac film for periodontitis therapy. Tropical Journal of Pharmaceutical Research, 2009; 8(1): 33-41.

Argoudelis AD, Fox JA, Mason DJ and Eble TE. New Lincomycin-Related Antibiotics Journal of the American Chemical Society, 1964; 86 (22): 5044-5045.

Baier RE and Glantz, PO. Characterization of oral in vivo films formed on different types of solid surfaces. Acta Odontologica Scandinavica, 1978; 36(5-6); 289-301.

Bumgardner JD, Wiser R, Gerard PD, Bergin P, Chestnutt B, Marini M, Ramsey V, Elder SH and Gilbert JA. Chitosan: potential use as a bioactive coating for orthopaedic and craniofacial/dental implants. Journal of Biomaterials Science, Polymer Edition, 2003; 14(5): 423-438.

Costa P and Lobo JMS. Modeling and comparison of dissolution profiles. European journal of pharmaceutical sciences, 2001; 13(2): 123-133.

Ganjoo R, Soni S and Ram V. Effect of Release Modifier on Hydrodynamically Balanced System of Ketoprofen for Sustained Delivery System. Inventi Rapid: NDDS, 2013; 2013(4): 283-288

Higuchi T. Rate of release of medicaments from ointment bases containing drugs in suspension, J Pharm Sci, 1961; 50: 874-875. 
Ikinci G, Şenel S, Akıncıbay H, Kaş S, Erciş S, Wilson CG, Hincal AA. Effect of chitosan on a periodontal pathogen Porphyromonas gingivalis. International journal of pharmaceutics, 2002; 235(1):121-127.

Jeffcoat MK, Bray KS, Ciancio SG, Dentino AR, Fine DH, Gordon JM, Gunsolley JC, Killoy WJ, Lowenguth RA, Magnusson NI and Offenbacher S. Adjunctive use of a subgingival controlled-release chlorhexidine chip reduces probing depth and improves attachment level compared with scaling and root planing alone. Journal of periodontology, 98; 69(9): 989-997.

Johnston D, Choonara YE, Kumar P, du Toit LC, van Vuuren S and Pillay V. Prolonged delivery of ciprofloxacin and diclofenac sodium from a polymeric fibre device for the treatment of peridontal disease. BioMed research international, 2013: 15 pages, doi:10.1155/2013/460936

Kang BS, Sul YT, Oh SJ, Lee HJ and Albrektsson T. XPS, AES and SEM analysis of recent dental implants. Acta biomaterialia, 2009; 5(6): .2222-2229.

King NM, Hiraishi N, Yiu CK, Pashley EL, Loushine RJ, Rueggeberg FA, Pashley DH and Tay FR. Effect of resin hydrophilicity on water-vapour permeability of dental adhesive films. European journal of oral sciences, 2005; 113(5): 436-442.

Korsmeyer RW, Gurny R, Doelker E, Buri P, Peppas NA. Mechanisms of solute release from porous hydrophilic polymers. Int $J$ Pharm, 1983; 15: 25-35.

Li X, Kolltveit KM, Tronstad L, Olsen I. Systemic Diseases Caused by Oral Infection. Clinical Microbiology Reviews. 2000; 13(4); 547-558.

Loesche WJ, Grossman NS. Periodontal Disease as a Specific, albeit Chronic, Infection: Diagnosis and Treatment. Clinical Microbiology Reviews. 2001; 14(4): 727-752. doi:10.1128/CMR.14.4.727-752.2001.

$\mathrm{Lu} \mathrm{Y}$ and Chen SC. Micro and nano-fabrication of biodegradable polymers for drug delivery. Advanced drug delivery reviews. 2004; 56(11): 1621-1633.

Mendyk A, Jachowicz R, Fijorek K, Dorozynski P, Kulinowski $\mathrm{P}$ and Polak S. KinetDS: an open source software for dissolution test data analysis. Dissolution Technologies, 2012; 19(1): 6-11.

Norling T, Lading P, Engström S, Larsson K, Krog N and Nissen SS. Formulation of a drug delivery system based on a mixture of monoglycerides and triglycerides for use in the treatment of periodontal disease. Journal of clinical periodontology, 1992; 19(9): 687692.

Panigrahi L, Ghosal SK, Pattnaik S, Maharana L, Barik BB. Effect of permeation enhancers on the release and permeation kinetics of Lincomycin hydrochloride gel formulations through mouse skin. Indian Journal of Pharmaceutical Sciences, 2006; 68(2): 205-211

Peschke U, Schmidt H, Zhang HZ and Piepersberg W. Molecular characterization of the lincomycin-production gene cluster of Streptomyces lincolnensis 78-11. Molecular Microbiology, 1995; 16: 1137-1156. doi:10.1111/j.1365-2958.1995.tb02338.x

Polson AM, Garrett S, Stoller NH, Bandt CL, Hanes PL, Killoy WJ, Southard GL, Duke SP, Bogle GC, Drisko CH et al. Multi-center comparative evaluation of subgingivally delivered sanguinarine and doxycycline in the treatment of periodontitis. II. Clinical results. $J$ Periodontol. 1997; 68(2): 119-126.
Rhim, JW, Hong SI, Park HM and Ng PK. Preparation and characterization of chitosan-based nanocomposite films with antimicrobial activity. Journal of agricultural and food chemistry, 2006; 54(16): 58145822 .

Rinaudo M. Chitin and chitosan: Properties and applications. Progr Poly Sci, 2006; 31: 603-632

SatoT, Ishii $\mathrm{T}$ and Okahata $\mathrm{Y}$. In vitro gene delivery mediated by chitosan. effect of $\mathrm{pH}$, serum, and molecular mass of chitosan on the transfection efficiency. Biomaterials, 2001; 22(15): 2075-2080.

Schwach-Abdellaoui K, Khadija N, Vivien-Castioni and Robert Gurny. Local delivery of antimicrobial agents for the treatment of periodontal diseases. European Journal of Pharmaceutics and Biopharmaceutics, 2000; 50 (1): 83-99.

Slots J and Rams TE. Antibiotics in periodontal therapy: advantages and disadvantages. Journal of clinical periodontology, 1990; 17(s1): 479-493.

Soni S, Verma A, Ram V. Evaluation of Chitosan-Hydroxy Propyl Methyl Cellulose as a Single Unit Hydrodynamically Balanced Sustained Release Matrices for Stomach Specific Delivery of Piroxicam. MOJ Bioequiv Availab, 2016; 2(1): 00014. DOI: 10.15406/mojbb.2016. 02.00014

Soskolne WA. Subgingival delivery of therapeutic agents in the treatment of periodontal diseases. Crit Rev Oral Biol Med. 1997; 8(2): $164-174$

Takasaki AA, Aoki A, Mizutani K, Schwarz F, Sculean A, Wang CY, Koshy G Romanos, G Ishikawa I and Izumi Y. Application of antimicrobial photodynamic therapy in periodontal and peri-implant diseases. Periodontology, 2009; 51(1): 109-140.

Tiwari P, Soni S, Ram V and Verma A. Raft forming buoyant $\mathrm{pH}$ dependent thixotropic gelling systems incorporated with gelucire 43/01 as a potential stomach specific drug delivery system for famotidine. Journal of Applied Pharmacy, 2015; 7(3): 183-202

Zhou X, Liu D, Liu H, Yang Q, Yao K, Wang X, Wang L and Yang X. Effect of low molecular weight chitosans on drug permeation through mouse skin: 1. Transdermal delivery of baicalin. Journal of pharmaceutical sciences, 2010; 99(7): 2991-2998.

\section{How to cite this article:}

Ganjoo R, Soni S, Ram V, Verma A. Medium Molecular Weight Chitosan as a Carrier for Delivery of Lincomycin Hydrochloride from Intra-pocket Dental Film: Design, Development, in vitro and ex vivo Characterization. J App Pharm Sci, 2016; 6 (10): 008-019. 